\title{
Complementary medicine use, views, and experiences: a national survey in England
}

\author{
Debbie Sharp, PhD ${ }^{1}$, Ava Lorenc, $\mathrm{PhD}^{2 *}$, Richard Morris, $\mathrm{PhD}^{3}$, Gene Feder, MD \\ Paul Little, FMedSci ${ }^{5}$, Sandra Hollinghurst, $\mathrm{PhD}^{6}$, Stewart W Mercer, PhD7, \\ Hugh MacPherson, PhD $^{8}$
}

${ }^{1}$ Professor of Primary Care, Centre for Academic Primary Care, Population Health Sciences, Bristol Medical School, University of Bristol, Bristol, UK; ${ }^{2}$ Senior Research Associate, Centre for Academic Primary Care, Population Health Sciences, Bristol Medical School, University of Bristol, Bristol, UK; ${ }^{3}$ Professor in Medical Statistics, Centre for Academic Primary Care, Population Health Sciences, Bristol Medical School, University of Bristol, Bristol, UK; ${ }^{4}$ Professor of Primary Care, Centre for Academic Primary Care, Population Health Sciences, Bristol Medical School, University of Bristol, Bristol, UK; ${ }^{5}$ Professor of Primary Care Research, Primary Medical Care, Faculty of Medicine, University of Southampton, Southampton, UK; ${ }^{6}$ Senior Lecturer in Health Economics, Centre for Academic Primary Care, Population Health Sciences, Bristol Medical School, University of Bristol, Bristol, UK; ${ }^{7}$ Chair in Primary Care Research, Primary Care and General Practice, Institute of Health and Wellbeing, University of Glasgow, Glasgow, UK; ${ }^{8}$ Professor of Acupuncture Research, Department of Health Sciences, University of York, York, UK

*For correspondence: ava. lorenc@bristol.ac.uk

Competing interests: The authors declare that no competing interests exist.

Received: 15 January 2018 Accepted: 23 July 2018

Published: 14 November 2018

Author Keywords:

Complementary Therapies, Surveys and Questionnaires, General Practice

(C) This article is Open Access: CC BY license (https:// creativecommons.org/licenses/ by/4.0/)

Copyright (C) 2018, The Authors; DOI:10.3399/

bjgpopen18X101614

\section{Abstract}

Background: In $2005,12 \%$ of the English population visited a complementary and alternative medicine (CAM) practitioner.

Aim: To obtain up-to-date general population figures for practitioner-led CAM use in England, and to discover people's views and experiences regarding access.

Design \& setting: A face-to-face questionnaire survey was commissioned. A nationally representative adult quota sample (aged $\geq 15$ years) was used.

Method: Ten questions were included within Ipsos MORI's weekly population-based survey. The questions explored 12-month practitioner-led CAM use, reasons for non-use, views on NHSprovided CAM, and willingness to pay.

Results: Of 4862 adults surveyed, 766 (16\%) had seen a CAM practitioner. People most commonly visited CAM practitioners for manual therapies (massage, osteopathy, chiropractic) and acupuncture, as well as yoga, pilates, reflexology, and mindfulness or meditation. Women, people with higher socioeconomic status (SES) and those in south England were more likely to access CAM. Musculoskeletal conditions (mainly back pain) accounted for $68 \%$ of use, and mental health $12 \%$. Most was through self-referral $(70 \%)$ and self-financing. GPs (17\%) or NHS professionals $(4 \%)$ referred and/or recommended CAM to users. These CAM users were more often unemployed, with lower income and social grade, and receiving NHS-funded CAM. Responders were willing to pay varying amounts for CAM; $22 \%$ would not pay anything. Almost two in five responders felt NHS funding and GP referral and/or endorsement would increase their CAM use.

Conclusion: CAM use in England is common for musculoskeletal and mental health problems, but varies by sex, geography, and SES. It is mainly self-referred and self-financed; some is GP-endorsed and/or referred, especially for individuals of lower SES. Researchers, patients, and commissioners 
should collaborate to research the effectiveness and cost-effectiveness of CAM and consider its availability on the NHS.

\section{How this fits in}

Figures from 2005 reported that $12 \%$ of the English population used practitioner-led CAM. This 2015 survey has found that $16 \%$ of the general population had used practitioner-led CAM in the previous 12 months. Most CAM use is self-referred, for musculoskeletal problems, particularly by women and those of higher SES, although some is GP-endorsed and/or referred, for individuals of lower SES. Researchers, patients, and commissioners should collaborate to research the effectiveness and cost-effectiveness of CAM and consider its availability on the NHS.

\section{Introduction}

CAM is 'a diverse group of health-related therapies and disciplines which are not considered to be a part of mainstream medical care' and includes osteopathy, chiropractic, acupuncture, herbal medicine, and homeopathy. ${ }^{1}$ This survey focused on practitioner-led CAM, for which the prevalence was $10 \%$ in 2001 (UK), ${ }^{2}$ and $12 \%$ in 2005 (England). ${ }^{3}$ If over-the-counter and/or self-care CAM are included, 12-month prevalence estimates of CAM use in Europe range from $0.3-86 \%{ }^{4}{ }^{\text {recent UK }}$ adult annual CAM use estimates were $28 \%$ (England only), ${ }^{5} 20 \%,{ }^{6}$ and $26 \%$ (England only) ${ }^{3}$ in 1998 , 1999, and 2005 respectively. A systematic review reported a $41 \%$ average 1 -year prevalence CAM use in the UK and $52 \%$ average lifetime prevalence. ${ }^{7}$ There has not been a national English survey since 2005 .

The evidence base for CAM varies widely. For musculoskeletal and mental health conditions, which are common in primary care, and were the focus of the authors' larger scoping study, $^{8}$ good quality reviews were identified with moderate to good quality evidence of effectiveness for yoga, ${ }^{9}$ osteopathy, ${ }^{10}$ acupuncture, ${ }^{11,12}$ and spinal manipulation and/or mobilisation ${ }^{12-14}$ for low back pain; acupuncture for myofascial trigger point pain; ${ }^{15}$ tai chi $^{16}$ and acupuncture ${ }^{17,18}$ for osteoarthritis; manual therapy, ${ }^{19}$ manipulation, ${ }^{20}$ and acupuncture ${ }^{12}$ for neck pain; acupuncture for fibromyalgia; ${ }^{21}$ mindfulness and/or meditation, ${ }^{22,23}$ and tai chi $^{24}$ for depression; ${ }^{25}$ meditation and/ or mindfulness-based stress reduction for anxiety; ${ }^{22,26}$ meditative and/or mind-body movement for sleep; ${ }^{27}$ and mindfulness for stress and distress. ${ }^{22}$

There is little up-to-date information on current NHS provision of CAM. A recent survey suggests that a million NHS acupuncture appointments are provided annually. ${ }^{28}$ A systematic review of surveys estimated that $>20 \%$ of UK physicians had 'used' CAM in their practice within the previous week (recommendations, referrals, provision of treatment, or self-administration), an average of $39 \%$ of physicians had referred to and 46\% had recommended CAM. ${ }^{7}$ A 2003 article found around half of general practices offered some CAM services, mainly acupuncture, osteopathy, and homeopathy. ${ }^{29}$ In $2009,19 \%$ of GPs were regularly treating patients with CAM; $56 \%$ had treated with, referred to, or endorsed CAM during the previous week. ${ }^{30}$

Given the lack of recent data on CAM use by the public or NHS CAM access, and in the light of the emphasis in the 2014 NHS Five Year Forward View on self-care, prevention, and wellbeing, ${ }^{31}$ the authors conducted a national survey with Ipsos MORI of the public's use of CAM and their views on CAM provision within the NHS.

\section{Method}

The aim of the survey was to obtain up-to-date figures on CAM use in the general population in England, and explore views and experiences regarding consulting CAM practitioners. The specific objectives were:

1. to identify the proportion of the population in England that had used practitioner-led CAM in the previous year, and explore reasons for non-use;

2. to identify the health conditions most commonly treated with CAM;

3. to identify how CAM is accessed and funded, and how much it costs individuals; and 
4. to obtain the public's views on models of CAM provision within the NHS and willingness to pay for CAM.

The authors commissioned Ipsos MORI (a UK market research company) to include 10 questions within their national, weekly 'Capibus' survey (https://www.ipsos-mori.com/ourexpertise/omnibusservices/capibus.aspx). This face-to-face computer-assisted survey, completed in people's homes, used a quota sample of all adults (aged $\geq 15$ years) in England. Quota sampling aims for a nationally representative sample of adults in England, based on age, sex, and working status, within four regions (South, North, Midlands, and London). The survey ran between 25 September and 18 October 2015.

The project team developed 10 survey questions (see Appendix) with input from Ipsos MORI, the project patient and public involvement group, and steering group. The questions included: whether practitioner-based complementary medicine had been used during the previous 12 months; reason for use; access; funding; cost; reasons for non-use; views on particular models of NHS CAM provision that might facilitate its use; and willingness to pay. Ipsos MORI provided basic demographic data. The authors combined income, social grade, and employment into SES. The authors defined CAM by showing participants a list of practitioners, including NHS professionals delivering CAM (for example, GP, physiotherapist, or nurse), adapted from that used by the National Library of Medicine's MeSH term 'Complementary therapies'. ${ }^{32}$ The list included most of the CAM included by Thomas and Hunt ${ }^{2,3}$ (but excluding crystal healing, dowsing, iridology, kinesiology, relaxation; adding art therapy, Bach flowers, biofeedback, craniosacral, emotional freedom technique, Feldenkrais, guided imagery, music therapy, pilates, qi gong, tai chi, Trager, and yoga). An open-ended question asked what help they were seeking from the CAM practitioner; free-text responses were coded.

Data were weighted by Ipsos MORI for the English adult population using region, social grade, age, working status, housing tenure, and ethnicity (white or black and minority ethnic), based on census data or mid-year estimates and National Readership Survey defined profiles. Analyses were mainly descriptive; statistical testing compared different groups. In addition to the univariable analyses, a multivariable analysis using logistic regression was conducted to test whether bivariable associations were independent of each other, estimating odds ratios with $95 \%$ confidence intervals. Not all aspects of CAM use were amenable to multivariable analysis; the authors excluded those with events less than 10 times the number of parameter estimates required in any specific model. ${ }^{33}$

\section{Results}

The final sample comprised 4862 adults (response rates unavailable). See Table 1 for participant characteristics.

\section{CAM use}

A total of 766 participants (16\% of sample) had seen a CAM practitioner (from the list) in the previous 12 months. Table 2 shows manual therapies were most common. The main route to a CAM practitioner was self-referral $(n=539,70 \%)$, followed by GP referral or recommendation $(n=133$, $17 \%)$. The majority of responders (67\%) paid in full for their CAM but, for $13 \%$ of CAM users, the NHS paid (the remaining $20 \%$ selected other options, such as 'another organisation such as a charity paid for all of it'). 'GP or NHS health professional-provided CAM' included physiotherapist-delivered CAM, 'traditional medicine', tai chi, yoga, osteopathy, acupuncture, and meditation and/ or mindfulness.

Table 3 shows univariable and multivariable demographic associations. CAM use was associated with being female, higher SES (higher social grade, higher household income, being employed) and living in the south of England (all $P<0.001$ ). Remarkably, few associations changed in the multivariable analysis. Only marital status and housing status were not independently associated with CAM use.

Musculoskeletal conditions, mainly back pain, accounted for $68 \%$ of CAM use (see Table 4). Men and those aged $>65$ years were more likely to cite musculoskeletal conditions, the latter mainly for arthritis. Musculoskeletal conditions were significantly more likely to be treated with massage, osteopathy, and chiropractic than were mental health conditions, which were more likely to be treated with meditation and/or mindfulness or reiki. Eleven percent of CAM use was non-conditionspecific, that is for prevention or general health. Women were more likely to use CAM for arthritis 
Table 1 Participant characteristics ( $n=4862$ )

Sex

Male

Female

Missing data

Age (years)

$15-24$

25-34

35-44

$45-54$

$55-64$

$65+$

Missing data

Social grade (based on occupation of chief income earner) ${ }^{a}$

B

C1

C2

D

E

Missing data

Household income (annual)

Up to $f 11499$

f11 500-£24 999

£25 000+

Missing data

Marital status

Married/living as

Single

Widowed/divorced/separated

Missing data

Working status

Working

In education

Not working

Missing data

Region of England

North

Midlands

South

London

Missing data

Ethnicity

White

Mixed

Table 1 continued on next page
$\%$

$\begin{array}{cc}2378 & 49 \\ 2484 & 51 \\ 0 & 0\end{array}$

$762 \quad 16$

$817 \quad 17$

$771 \quad 16$

$832 \quad 17$

$656-13$

$1024 \quad 21$

0

0

168

$1163 \quad 24$

$1317 \quad 27$

1053222

$744 \quad 15$

$416 \quad 9$

$1<1$

650

$804 \quad 17$

$1664 \quad 34$

$1744 \quad 36^{b}$

$2801 \quad 58$

$1407 \quad 29$

$636 \quad 13$

$18<1$

2676

$398 \quad 8$

$1788 \quad 37$

$0 \quad 0$

$1395 \quad 29$

$1057 \quad 22$

$1697 \quad 35$

$713 \quad 15$

0

$4171 \quad 86$

$46-1$


Table 1 continued

\begin{tabular}{|c|c|c|}
\hline & $n$ & $\%$ \\
\hline Asian & 452 & 9 \\
\hline Black & 130 & 3 \\
\hline Other & 53 & 1 \\
\hline Missing data & 10 & $<1$ \\
\hline \multicolumn{3}{|l|}{ Housing tenure } \\
\hline Mortgage/owned & 3028 & 62 \\
\hline Rented & 1751 & 36 \\
\hline Other & 38 & 1 \\
\hline Missing data & 45 & 1 \\
\hline \multicolumn{3}{|c|}{$\begin{array}{l}\text { aBased on National Readership Survey categories: } \\
\text { A: High managerial, administrative, or professional } \\
\text { B: Intermediate managerial, administrative, or professional } \\
\text { C1: Supervisory, clerical and junior managerial, administrative, or professional } \\
\text { C2: Skilled manual workers } \\
\text { D: Semi and unskilled manual workers } \\
\text { E: State pensioners, casual, or lowest grade workers, unemployed with state benefits only } \\
\text { bMissing data of around one-third is usual for the Capibus survey }\end{array}$} \\
\hline
\end{tabular}

and minor mental health conditions. The majority $(n=632)$ used CAM for one condition; $n=101$ used it for two conditions; $n=25$ for three conditions; $n=6$ for four conditions; $n=1$ for five conditions; and $n=1$ for six conditions.

Table 5 shows the pathways to (GP referred and/or recommended, or self-referred) and payment (NHS or not) for the most popular CAM. The most commonly used CAM therapies (shown in Table 5) were similar across all four categories.

Table 6 shows that GP-referred and/or recommended users were more likely to be aged $<24$ years or $>55$ years, of lower SES, living in the north of England, renting, and Asian. Apart from age, all these demographic associations were reversed for self-referred CAM users. GPreferred and/or recommended users were more likely to have had their CAM paid for by the NHS, although $27 \%$ of this subgroup, had paid something towards the CAM. The condition being treated was not associated with the route to CAM or NHS payment.

\section{Non-use of CAM}

Not needing any health care was the main reason cited by the majority (63\%) of non-users; for $16 \%$ it had not occurred to them. Lack of need was more commonly cited by those with higher SES and less commonly by Asian and Black responders. Six percent stated that they did not believe in CAM. Concern about practitioners' professional regulation or qualifications was more common in social grades A and B. Not being available locally was most commonly mentioned by responders in London.

\section{Factors relating to CAM use}

When given a list of possible models of CAM provision, including funding, and asked: 'If you had a health problem you thought complementary or alternative medicine could help with, which, if any, of the following statements would encourage you to use it?' $39 \%$ of responders said they would be more likely to use complementary medicine if it was free (NHS-funded), 35\% if their GP mentioned it might help, and $27 \%$ if their GP referred them.

In general, NHS-related factors (limitations of NHS care, part NHS-payment, or a CAM practitioner who was an NHS professional or NHS regulated) were more often cited by those who were female, had higher income, had a mortgage, and were employed.

CAM users were more likely to respond: 'If I thought it would enhance the care I was already receiving.' Non-users were more likely to respond: 'If my GP mentioned it might help.' Non-users were also more likely to respond: 'If my GP referred me.' Those who were not using CAM owing to 
Table 2 Characteristics of CAM use $(n=766)$

\section{Type of CAM practitioner}

Massage practitioner

Osteopath

Acupuncturist

Chiropractor

Yoga teacher

Physiotherapist-delivered CAM

Pilates teacher

Reflexologist

Meditation and/or mindfulness teacher

Homeopath

Reiki practitioner

Hypnotherapist

Herbalist

n

$\%$

Chinese herbal medical practitioner

Other

Number of times they saw the CAM practitioner in the past 12 months

Once a year

$143 \quad 19$

91

88

87

52

41

28

22

20

20

17

15

2-3 times

$185 \quad 24$

$4-6$ times

211

177

Once or twice a month

$115 \quad 15$

Once or twice a week

More than twice a week

Don't know

$68 \quad 9$

\section{Route to CAM practitioner}

I found them myself or they were recommended by friend/family

My GP referred or recommended me

Another NHS health professional (for example consultant) referred me

Another complementary practitioner referred or recommended me

My GP or another NHS health professional I was seeing provided the complementary treatment themselves

Through company or work insurance

Other

2

7

5

3

3

3

3

2

2

2

10


Table 2 continued

\begin{tabular}{|c|c|c|}
\hline & n & $\%$ \\
\hline Between $f 11$ and $f 20$ & 55 & 10 \\
\hline Between $f 21$ and $f 30$ & 126 & 23 \\
\hline Between $£ 31$ and $£ 40$ & 163 & 29 \\
\hline Between $£ 41$ and $£ 50$ & 73 & 13 \\
\hline Between $f 51$ and $\mathrm{f} 60$ & 35 & 6 \\
\hline Between $\mathrm{f60}$ and $£ 100$ & 23 & 4 \\
\hline Over $f 100$ & 5 & 1 \\
\hline Prefer not to say/don't know & 3 & $<1$ \\
\hline
\end{tabular}

lack of healthcare need were more likely to cite NHS endorsement as encouraging them to use CAM. Those who were not using CAM because 'it hasn't occurred to me' were more likely to say they would consider CAM if they 'had to wait a long time for NHS care' or 'NHS treatment was not helping'.

\section{Cost of CAM and willingness to pay}

For the 560 CAM users who provided cost data, the majority paid $f 21-f 40$ per visit ( $n=289,52 \%$ of responders), as shown in Table 2. The only demographic association was that those in the south or London were more likely to pay $£ 41-£ 50$ and those in London were more likely to pay $£ 60-£ 100$ than any other region.

Non-users were asked: 'If you had a health problem you thought would improve from seeing a complementary or alternative practitioner, what is the most you would be willing to pay for each visit?' Amounts cited varied widely; $17 \%$ cited 'between $f 11$ and $f 20$ '; $16 \%$ 'between $f 21$ and f 10 '; and $22 \%$ said they would not be willing to pay for it at all. High earners, those in work, and those of higher social grade were willing to pay more.

\section{Discussion}

\section{Summary}

Sixteen percent of the surveyed adult population (aged $\geq 15$ years) in England had seen a CAM practitioner in the last 12 months, mainly for manual therapies and most commonly for musculoskeletal conditions (mainly back pain), followed by mental health. Use was more commonly associated with being female, of higher SES and living in the south of England. Most users paid for the CAM themselves. Although the majority of CAM use was via self-referral, a small proportion was GP referred and/or recommended, for a range of conditions and mainly for acupuncture, physiotherapist-delivered CAM, chiropractic, and osteopathy. GP-referred CAM was more common in lower SES groups and more often paid for by the NHS. Willingness to pay for CAM varied widely; for example, $22 \%$ of responders said they would not be willing to pay anything, and higher SES responders were willing to pay more.

\section{Strengths and limitations}

Incorporating questions on CAM within a routine national survey was efficient. The Capibus methodology obtained a nationally representative sample, using face-to-face interviews at people's homes, rigorous geographical sampling, and quotas for demographic characteristics. Data were comprehensively validated and weighted to correct for minor deficiencies or bias in the sample. Although overall response rates are not available, being part of the routine Capibus survey is likely to have avoided the pro-CAM response bias described for other CAM surveys. ${ }^{34}$ 
Table 3 Univariable and multivariable associations of overall CAM use

\begin{tabular}{|c|c|c|c|c|c|}
\hline \multirow{2}{*}{ Factor } & \multirow[b]{2}{*}{ Category } & \multicolumn{2}{|c|}{ Univariable analysis } & \multicolumn{2}{|c|}{ Multivariable analysis } \\
\hline & & Odds ratio $(95 \% \mathrm{Cl})$ & $P$ value & Odds ratio $(95 \% \mathrm{Cl})$ & $P$ value \\
\hline Sex & Male & 1 & & 1 & \\
\hline \multirow[t]{4}{*}{ Age } & $15-24$ & 1 & & 1 & \\
\hline & $25-34$ & 1.75 (1.28 to 2.4$)$ & $<0.001$ & 1.81 (1.24 to 2.65$)$ & 0.002 \\
\hline & $55-64$ & 2.29 (1.67 to 3.14$)$ & $<0.001$ & 2.09 (1.38 to 3.15$)$ & $<0.001$ \\
\hline & $65+$ & 1.48 (1.09 to 2.02 ) & 0.012 & 1.49 (0.95 to 2.34$)$ & 0.081 \\
\hline \multirow[t]{2}{*}{ Ethnicity } & White & 1 & & 1 & \\
\hline & Mixed & 1.49 (0.75 to 2.98$)$ & 0.26 & 1.73 (0.93 to 3.24$)$ & 0.085 \\
\hline \multirow[t]{2}{*}{ Housing tenure } & Owner & & & 1 & \\
\hline & Rented & 0.61 (0.51 to 0.72$)$ & $<0.001$ & 0.84 (0.68 to 1.04$)$ & 0.11 \\
\hline \multirow[t]{3}{*}{ Income } & Low (up to f11 499) & 1 & & \multirow{3}{*}{\multicolumn{2}{|c|}{$\begin{array}{l}\text { Not conducted, due to } 30 \% \text { missing } \\
\text { data }\end{array}$}} \\
\hline & Medium (f11 500-f24 999) & 1.13 (0.83 to 1.52$)$ & 0.43 & & \\
\hline & High ( $f 25000$ or more) & 1.78 (1.38 to 2.31$)$ & $<0.001$ & & \\
\hline \multirow[t]{3}{*}{ Marital status } & Married & 1 & & 1 & \\
\hline & Single & 0.72 (0.6 to 0.86$)$ & $<0.001$ & 1.21 (0.96 to 1.52$)$ & 0.11 \\
\hline & Widowed/divorced/separated & 0.83 (0.65 to 1.05$)$ & 0.12 & 1.04 (0.79 to 1.38$)$ & 0.77 \\
\hline Region & North & 1 & & & \\
\hline & Unemployed & 0.65 (0.55 to 0.77$)$ & $<0.001$ & 0.74 (0.59 to 0.92$)$ & 0.008 \\
\hline Social grade & (per grade) & 0.77 (0.73 to 0.82 ) & $<0.001$ & 0.82 (0.76 to 0.88$)$ & $<0.001$ \\
\hline
\end{tabular}

The authors could only include a limited number and length of questions. Some questions had a poor response, which limited sub-group analyses.

As for all Ipsos MORI surveys, interviewers did not guide responders or provide clarification beyond the written questions and prompts. Some responders may have misunderstood the authors' CAM definition, particularly CAM delivered by an NHS practitioner; for example, mindfulness within NHS mental health services. Recall bias may have been present, particularly for specific questions such as the cost of the CAM.

\section{Comparison with existing literature}

Practitioner-led CAM use was about 5\% higher than previous national (UK and England) surveys. ${ }^{2,3}$ This may relate to the authors' wider CAM definition, which included 11 more therapies than Hunt et $a l^{3}$ or increased CAM use since 2005. Exercise-based CAM (pilates, qi gong, tai chi, yoga), used by up to $7 \%$ of users, may account for this study's higher prevalence figure. Only osteopaths and acupuncturists featured in both the present survey's and previous national surveys' top five most commonly accessed practitioners, ${ }^{2,3}$ although chiropractors and massage practitioners 
Table 4 Health conditions treated by a CAM practitioner $(n=766)$

\begin{tabular}{|c|c|c|}
\hline & n & $\%$ \\
\hline Musculoskeletal (net) & 520 & 68 \\
\hline Back pain & 292 & 38 \\
\hline Other musculoskeletal pain (neck pain, shoulder pain, knee pain) & 172 & 22 \\
\hline Arthritis (osteo- or rheumatoid) & 48 & 6 \\
\hline Headaches/migraines & 33 & 4 \\
\hline Other chronic pain & 29 & 4 \\
\hline Fibromyalgia & 10 & 1 \\
\hline Other (net) & 223 & 2 \\
\hline Women's health & 25 & 3 \\
\hline Preventative & 23 & 3 \\
\hline Relaxation & 23 & 3 \\
\hline General health/wellbeing & 22 & 3 \\
\hline Exercise/keeping fit & 17 & 2 \\
\hline Digestive problems & 13 & 2 \\
\hline Other & 124 & 16 \\
\hline Mental health (net) & 92 & 12 \\
\hline Minor mental health symptoms (minor depression, anxiety, stress) & 50 & 7 \\
\hline Tiredness or fatigue & 22 & 3 \\
\hline Sleep problems/insomnia & 15 & 2 \\
\hline Serious mental health conditions & 9 & 1 \\
\hline Chronic fatigue syndrome/myalgic encephalomyelitis & 8 & 1 \\
\hline Don't know & 4 & 1 \\
\hline No answer & 6 & 1 \\
\hline
\end{tabular}

were in the authors' one previous survey. The emphasis on manual therapies (massage, osteopathy, and chiropractic), acupuncture, and yoga in the survey reflects current evidence (see Introduction). Pilates and reflexology were popular but have less evidence. Tai chi has some evidence but was not popular.

CAM was most commonly used for musculoskeletal conditions in a UK survey and an EU review. ${ }^{4,5}$ Using CAM for low back pain and arthritis probably reflects the general prevalence of these conditions, ${ }^{35-37}$ and possibly the evidence base for CAM. Having pain, anxiety, depression, or a long-term condition has been associated with seeing a CAM practitioner ${ }^{3}$ and CAM users may more often have multimorbidity. ${ }^{38}$

This study's demographic associations with CAM use have previously been reported: being female, ${ }^{3-5,38-40}$ higher social grade ${ }^{2}$ and income, ${ }^{2,38,39}$ and being employed. ${ }^{3}$ The first may reflect women's greater use of health care. ${ }^{41}$ Education is associated with social grade, income, and employment and is a stronger predictor of CAM use than income. ${ }^{38}$

Reasons for non-use of CAM are rarely explored, ${ }^{42}$ but often include lack of need for any health care ${ }^{42,43}$ confirming perceived need as predicting healthcare use. ${ }^{38}$ CAM users may use more health care in general, ${ }^{39,44}$ perhaps owing to chronic health conditions. ${ }^{44}$ Although pro-CAM beliefs, for example spirituality, predict CAM use, ${ }^{45}$ strong anti-CAM beliefs, for example safety concerns or poor availability, rarely predict non-use. ${ }^{42,43}$

Despite the small proportion of GP referred and/or recommended CAM, a significant proportion of GPs (19\%) endorse CAM in their practice. ${ }^{30}$ However, decreasing GP referral and/ or recommendation from 1999 (38\%) to 2009 (19\%) was attributed to either increased scepticism or NHS financial pressures. ${ }^{30}$ Acupuncture being a common GP referred and/or recommended CAM 
Table 5 Pathways to and payment for practitioners offering 16 most popular CAM therapies

\begin{tabular}{|c|c|c|c|c|c|c|c|c|c|c|}
\hline & & $\begin{array}{l}\text { referred/ } \\
\text { pmended } \\
n=133)\end{array}$ & & $\begin{array}{l}\text { F-referred } \\
=539)\end{array}$ & $P$ value & & $\begin{array}{l}\text { S paid for } \\
\text { me or all } \\
=117 \text { ) }\end{array}$ & NHS & $\begin{array}{l}\text { did not pay } \\
=649)\end{array}$ & $P$ value \\
\hline & $n$ & $\begin{array}{c}\% \\
\text { (of column) }\end{array}$ & $n$ & $\begin{array}{c}\% \\
\text { (of column) }\end{array}$ & & $n$ & $\begin{array}{c}\% \\
\text { (of column) }\end{array}$ & $n$ & $\begin{array}{c}\% \\
\text { (of column) }\end{array}$ & \\
\hline Acupuncture ${ }^{a}$ & 22 & 16 & 52 & 10 & 0.021 & 21 & 29 & 67 & 12 & 0.017 \\
\hline Physiotherapist-delivered $\mathrm{CAM}^{\mathrm{ab}}$ & 20 & 15 & 15 & 3 & $<0.001$ & 15 & 21 & 26 & 5 & $<0.001$ \\
\hline Chiropractic $^{a}$ & 13 & 10 & 67 & 13 & 0.42 & 5 & 7 & 82 & 14 & 0.009 \\
\hline Osteopathy & 11 & 8 & 75 & 14 & 0.09 & 10 & 14 & 80 & 14 & 0.28 \\
\hline Massage $^{a}$ & 9 & 6 & 110 & 20 & $<0.001$ & 10 & 14 & 133 & 23 & 0.002 \\
\hline Yoga ${ }^{a}$ & 4 & 3 & 45 & 8 & 0.036 & 2 & 3 & 50 & 9 & 0.015 \\
\hline Pilates & 3 & 2 & 22 & 4 & 0.34 & 1 & 1 & 27 & 5 & 0.11 \\
\hline Reflexology & 1 & 1 & 19 & 4 & 0.15 & 1 & 1 & 21 & 4 & 0.23 \\
\hline Homeopathy & 1 & 1 & 17 & 3 & 0.13 & 0 & 0 & 20 & 4 & 0.057 \\
\hline Meditation/ mindfulness & 4 & 3 & 12 & 2 & 0.58 & 4 & 6 & 16 & 3 & 0.53 \\
\hline Reiki & 2 & 1 & 13 & 2 & 0.74 & 1 & 1 & 16 & 3 & 0.49 \\
\hline Hypnotherapy & 2 & 1 & 12 & 2 & 0.62 & 1 & 1 & 14 & 2 & 0.71 \\
\hline Herbal medicine & 3 & 2 & 10 & 2 & 0.74 & 1 & 1 & 13 & 2 & 0.39 \\
\hline Chinese herbal medicine & 1 & 1 & 11 & 2 & 0.48 & 1 & 1 & 11 & 2 & 0.50 \\
\hline Traditional medicine $\mathrm{e}^{\mathrm{ac}}$ & 6 & 5 & 3 & 1 & 0.003 & 9 & 8 & 2 & $>1$ & $<0.001$ \\
\hline Nutritional therapy & 3 & 2 & 3 & 1 & 0.09 & 3 & 3 & 7 & 1 & 0.19 \\
\hline
\end{tabular}

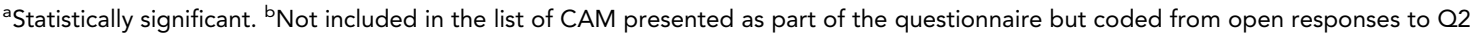
'May have been interpreted by participants as meaning conventional medicine.

may reflect its practice by NHS clinicians. ${ }^{28}$ GPs may have referred to or recommended chiropractic and osteopathy due to their statutory regulation.

Willingness to pay for CAM appeared to be based on ability to pay (that is, working and earning more), and free or low-cost CAM might increase use. Older and lower SES patients perhaps cannot afford CAM (they used GP referred and/or recommended and NHS-funded CAM). CAM is primarily paid for by the patient and is accessed outside NHS care, and is used, therefore, by more affluent groups. ${ }^{46}$ The relationship with income may also be due to availability (less CAM in low-income areas) and accessibility (barriers attending CAM appointments among those with lower-income jobs). ${ }^{47}$

\section{Implications for practice and research}

Future surveys could include larger samples (for subgroup analyses for CAM types), questions on 12 month or 'ever' use, perceived benefit, detail on health conditions, multiple uses of CAM, views on NHS integration, and more detail on willingness to pay.

These findings raise the question as to whether GPs and other NHS professionals should routinely ask patients about CAM use, particularly for back pain and other musculoskeletal conditions. ${ }^{3}$

Ability to pay may be a factor in accessing CAM (indicated by the association of CAM use with higher SES; lower SES responders being more likely to be GP-referred to CAM; and responders stating that they may use more CAM if the NHS provided services, and GPs endorsed and/or referred them). Integration of CAM into the NHS through primary care could promote continuity of care, safety, and balance of power. ${ }^{48}$ An integrative medicine approach includes many of the values recently included in UK health policy documents; for example, Five Year Forward View. ${ }^{49}$ It is patient-centred, as discussed in 2010, ${ }^{50}$ focuses on prevention, and emphasises patient self-management and person- and community-centred approaches to health and wellbeing. ${ }^{31}$ Many of these values underpin social prescribing, which is an increasingly popular model of health care. ${ }^{51}$ There seems to be significant patient demand for $\mathrm{CAM}^{52}$ and more holistic approaches, ${ }^{48}$ and a view that CAM may improve patient satisfaction. ${ }^{53}$ 
Table 6 Cross tabulation of demographics and access route to CAM practitioners

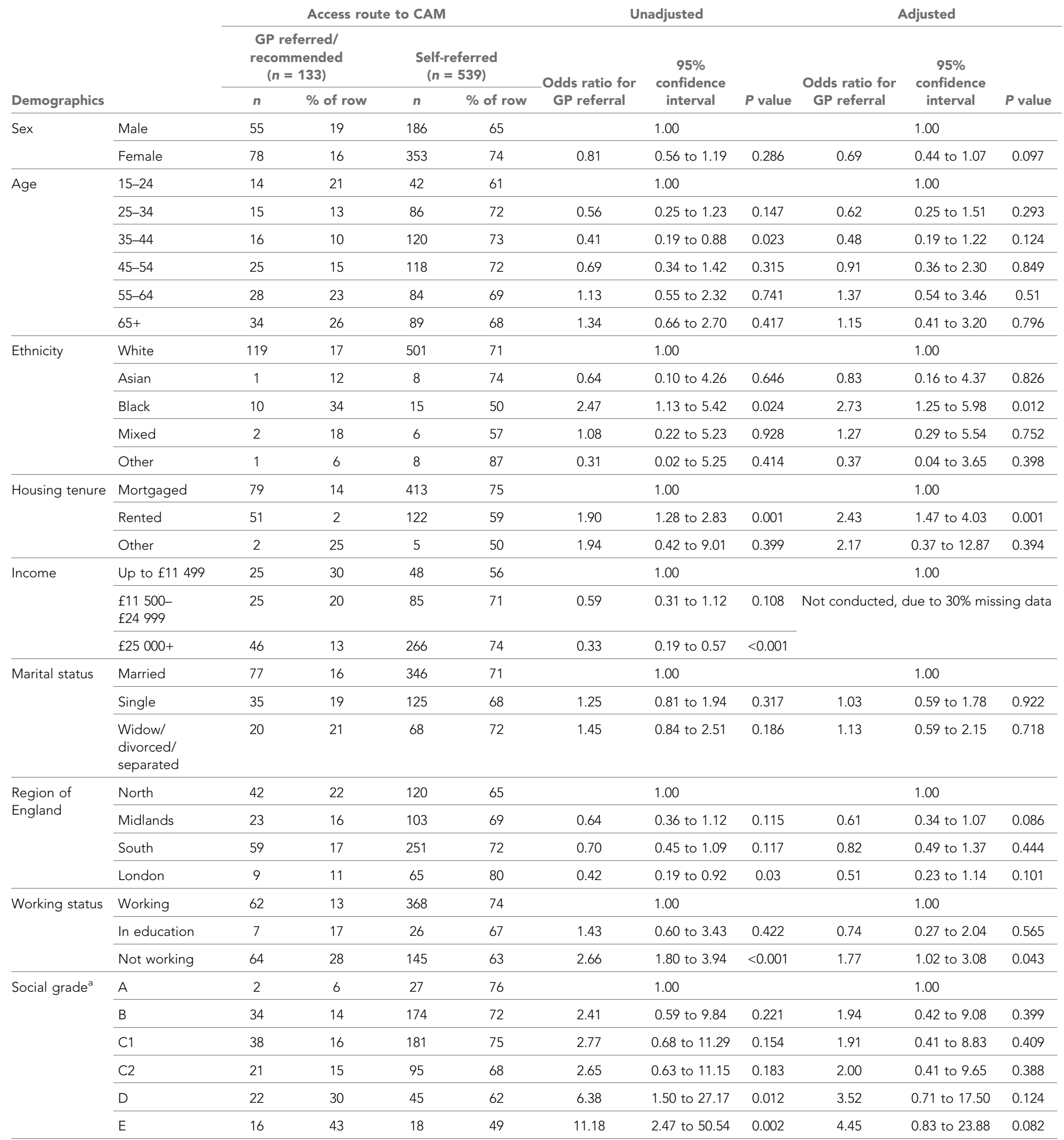

a Based on National Readership Survey categories:

A: High managerial, administrative, or professional

B: Intermediate managerial, administrative, or professional

C1: Supervisory, clerical and junior managerial, administrative, or professional

C2: Skilled manual workers

D: Semi and unskilled manual workers

E: State pensioners, casual, or lowest grade workers, unemployed with state benefits only 
However, such NHS endorsement would clearly need to be evidence based. For CAM with sufficient evidence for NHS integration, two models of integration may be possible. In 'selective incorporation' NHS staff practise CAM or CAM practitioners work on NHS premises. ${ }^{54}$ In Weise's integration model, GPs refer to CAM services. ${ }^{55}$ The latter may be more feasible, and could fit into a social prescribing model ${ }^{56}$ or the Professional Standards Authority's 'Let's Work Together' campaign. ${ }^{57}$ Another model is integrated personal commissioning, which enables people with chronic conditions to control their NHS and/or social care resources and 'micro-commission' their care. $^{58}$

Referral to CAM via the NHS also raises cost implications. Few responders were willing to pay the full cost (approximately $\mathrm{f} 60$ per visit in the UK) of CAM, and $13 \%$ said they would consider CAM if it was partly NHS-funded. Co-payment by patients is a contentious issue but, where the evidence base is good, the NHS may need to respond to a changing, consumerist society. ${ }^{49,59,60}$ There is little published about co-payment for CAM.

Complementary medicine is commonly used in England, particularly for musculoskeletal and mental health problems, and by affluent groups paying privately. However, less well-off people are also being GP-referred for NHS-funded treatments. For CAM with evidence of effectiveness (and costeffectiveness), those of lower SES may be unable to access potentially useful interventions, and access via GPs may be able to address this inequality. Researchers, patients, and commissioners should collaborate to research the effectiveness and cost-effectiveness of CAM, and consider its availability on the NHS. ${ }^{34}$

\section{Funding}

The report is based on independent research commissioned and funded by the NIHR Policy Research Programme (The Effectiveness And Cost Effectiveness Of Complementary And Alternative Medicine (CAM) For Multimorbid Patients With Mental Health And Musculoskeletal Problems In Primary Care In The UK: A Scoping Study). The views expressed in the publication are those of the author(s) and not necessarily those of the NHS, the NIHR, the Department of Health, arms length bodies, or other government departments.

\section{Ethical approval}

The study was approved by the University of Bristol Faculty of Medicine and Dentistry Research Ethics Committee (FREC) on 3 July 2015 (reference 21603).

\section{Provenance}

Freely submitted; externally peer reviewed.

\section{Acknowledgements}

The authors are very grateful to the team at Ipsos MORI for their assistance and to all the participants who completed the survey.

\section{References}

1. The House of Lords. Science and technology - sixth report. What is complementary and alternative medicine? Growing use of CAM in the United Kingdom. 2000. https://publications.parliament.uk/pa/ld1 99900/ldselect/ldsctech/123/12301.htm (accessed 9 Oct 2018).

2. Thomas K, Coleman P. Use of complementary or alternative medicine in a general population in Great Britain. Results from the National Omnibus survey. J Public Health (Oxf) 2004; 26(2): 152-157. doi: 10.1093/ pubmed/fdh139

3. Hunt KJ, Coelho HF, Wider B, et al. Complementary and alternative medicine use in England: results from a national survey. Int J Clin Pract 2010; 64(11): 1496-1502. doi: 10.1111/j.1742-1241.2010.02484.x

4. Eardley S, Bishop FL, Prescott $P$, et al. A systematic literature review of complementary and alternative medicine prevalence in EU. Forsch Komplementmed 2012; 19(Suppl 2): 18-28. doi: 10.1159/000342708

5. Thomas KJ, Nicholl JP, Coleman P. Use and expenditure on complementary medicine in England: a population based survey. Complement Ther Med 2001; 9(1): 2-11. doi: 10.1054/ctim.2000.0407

6. Ernst E, White A. The BBC survey of complementary medicine use in the UK. Complement Ther Med 2000; 8(1): 32-36. doi: 10.1016/S0965-2299(00)90833-1

7. Posadzki P, Alotaibi A, Ernst E. Prevalence of use of complementary and alternative medicine (CAM) by physicians in the UK: a systematic review of surveys. Clin Med 2012; 12(6): 505-512. doi: 10.7861/ clinmedicine.12-6-505 
8. Lorenc A, Feder G, MacPherson $\mathrm{H}$, et al. Scoping review of systematic reviews of complementary medicine for musculoskeletal and mental health conditions. BMJ Open 2018; 8(10):e020222. doi: 10.1136/bmjopen2017-020222

9. Cramer $\mathrm{H}$, Lauche $\mathrm{R}$, Haller $\mathrm{H}$, et al. A systematic review and meta-analysis of yoga for low back pain. Clin J Pain 2013; 29(5): 450-460. doi: 10.1097/AJP.0b013e31825e1492

10. Franke H, Franke JD, Fryer G. Osteopathic manipulative treatment for nonspecific low back pain: a systematic review and meta-analysis. BMC Musculoskelet Disord 2014; 15: 286. doi: 10.1186/1471-2474-15286

11. Xu M, Yan S, Yin X, et al. Acupuncture for chronic low back pain in long-term follow-up: a meta-analysis of 13 randomized controlled trials. Am J Chin Med 2013; 41(1): 1-19. doi: 10.1142/S0192415X13500018

12. Furlan AD, Yazdi F, Tsertsvadze A, et al. Complementary and alternative therapies for back pain II. Evid Rep Technol Assess 2010; 194(194): 1-764.

13. Rubinstein SM, van Middelkoop M, Assendelft WJ, et al. Spinal manipulative therapy for chronic low-back pain: an update of a Cochrane review. Spine 2011; 36(13): E825-846. doi: 10.1097/BRS.0b013e3182197fe1

14. Rubinstein SM, Terwee CB, Assendelft WJ, et al. Spinal manipulative therapy for acute low-back pain. Cochrane Database Syst Rev 2012; 9(9):Cd008880. doi: 10.1002/14651858.CD008880.pub2

15. Liu L, Huang QM, Liu QG, et al. Effectiveness of dry needling for myofascial trigger points associated with neck and shoulder pain: a systematic review and meta-analysis. Arch Phys Med Rehabil 2015; 96(5): 944955. doi: 10.1016/j.apmr.2014.12.015

16. Lauche $R$, Langhorst J, Dobos $G$, et al. A systematic review and meta-analysis of tai chi for osteoarthritis of the knee. Complement Ther Med 2013; 21(4): 396-406. doi: 10.1016/j.ctim.2013.06.001

17. Corbett MS, Rice SJ, Madurasinghe $V$, et al. Acupuncture and other physical treatments for the relief of pain due to osteoarthritis of the knee: network meta-analysis. Osteoarthritis Cartilage 2013; 21(9): 1290-1298. doi: 10.1016/j.joca.2013.05.007

18. Manheimer E, Cheng K, Linde K, et al. Acupuncture for peripheral joint osteoarthritis. Cochrane Database Syst Rev 2010; 38(4):CD001977. doi: 10.1002/14651858.CD001977.pub2

19. Miller J, Gross A, D'Sylva J, et al. Manual therapy and exercise for neck pain: a systematic review. Man Ther 2010; 15(4): 334-354. doi: 10.1016/j.math.2010.02.007

20. Gross A, Langevin P, Burnie SJ, et al. Manipulation and mobilisation for neck pain contrasted against an inactive control or another active treatment. Cochrane Database Syst Rev 2015; 17(2):CD004249. doi: 10. 1002/14651858.CD004249.pub4

21. Deare JC, Zheng Z, Xue CC, et al. Acupuncture for treating fibromyalgia. Cochrane Database Syst Rev 2013; 5(5):CD007070. doi: 10.1002/14651858.CD007070.pub2

22. de Vibe $M$, Arlid $B$, Elizabeth $T$, et al. Mindfulness based stress reduction (MBSR) for improving health, quality of life, and social functioning in adults. 2012. https://campbellcollaboration.org/library/mindfulnessstress-reduction-for-adults.html( accessed 10 Oct 2018).

23. Goyal M, Singh S, Sibinga EM, et al. Meditation programs for psychological stress and well-being: a systematic review and meta-analysis. JAMA Intern Med 2014; 174(3): 357-368. doi: 10.1001/jamainternmed. 2013.13018

24. Chi I, Jordan-Marsh M, Guo M, et al. Tai chi and reduction of depressive symptoms for older adults: a metaanalysis of randomized trials. Geriatr Gerontol Int 2013; 13(1): 3-12. doi: 10.1111/j.1447-0594.2012.00882.x

25. Klainin-Yobas $P$, Oo WN, Suzanne Yew PY, et al. Effects of relaxation interventions on depression and anxiety among older adults: a systematic review. Aging Ment Health 2015; 19(12): 1043-1055. doi: 10.1080/ 13607863.2014.997191

26. Chen KW, Berger CC, Manheimer E, et al. Meditative therapies for reducing anxiety: a systematic review and meta-analysis of randomized controlled trials. Depress Anxiety 2012; 29(7): 545-562. doi: 10.1002/da. 21964

27. Wu WW, Kwong E, Lan XY, et al. The effect of a meditative movement intervention on quality of sleep in the elderly: a systematic review and meta-analysis. J Altern Complement Med 2015; 21(9): 509-519. doi: 10. 1089/acm.2014.0251

28. Hopton AK, Curnoe $S$, Kanaan $M$, et al. Acupuncture in practice: mapping the providers, the patients and the settings in a national cross-sectional survey. BMJ Open 2012; 2(1): e000456. doi: 10.1136/bmjopen2011-000456

29. Thomas KJ, Coleman $P$, Nicholl JP. Trends in access to complementary or alternative medicines via primary care in England: 1995-2001 results from a follow-up national survey. Fam Pract 2003; 20(5): 575-577. doi: 10.1093/fampra/cmg514

30. Perry R, Dowrick C, Ernst E. Complementary medicine and general practice in an urban setting: a decade on. Prim Health Care Res Dev 2014; 15(3): 262-267. doi: 10.1017/S1463423613000182

31. NHS England. Five Year Forward View. 2014. https://www.england.nhs.uk/ourwork/futurenhs/nhs-five-yearforward-view-web-version/ (accessed 10 Oct 2018).

32. National Library of Medicine. Complementary Therapies. 2002. https://www.ncbi.nlm.nih.gov/mesh/?term= complementary+medicine (accessed 1 Nov 2018).

33. Pavlou M, Ambler G, Seaman SR, et al. How to develop a more accurate risk prediction model when there are few events. BMJ 2015; 351: h3868. doi: 10.1136/bmj.h3868

34. Posadzki P, Watson LK, Alotaibi $A$, et al. Prevalence of use of complementary and alternative medicine (CAM) by patients/consumers in the UK: systematic review of surveys. Clin Med (Lond) 2013; 13(2): 126-131. doi: 10.7861/clinmedicine.13-2-126 
35. Maniadakis N, Gray A. The economic burden of back pain in the UK. Pain 2000; 84(1): 95-103. doi: 10.1016/ S0304-3959(99)00187-6

36. Arthritis Research UK. Osteoarthritis in general practice. 2013. http://www.arthritisresearchuk.org/ /media/ Files/Policy\%20files/Policy\%20pages\%20files/Keel_Data_Report_digital_output.ashx?la=en (accessed 1 Nov 2018).

37. Arthritis Research UK. Rheumatoid arthritis. 2013. https://www.versusarthritis.org/about-arthritis/conditions/ rheumatoid-arthritis/ (accessed 7 Nov 2018).

38. Bishop FL, Lewith GT. Who uses CAM? A narrative review of demographic characteristics and health factors associated with CAM use. Evid Based Complement Alternat Med 2010; 7(1): 11-28. doi: 10.1093/ecam/ nen023

39. Reid R, Steel A, Wardle J, et al. Complementary medicine use by the Australian population: a critical mixed studies systematic review of utilisation, perceptions and factors associated with use. BMC Complement Altern Med 2016; 16(1): 1-23. doi: 10.1186/s12906-016-1143-8

40. Laiyemo MA, Nunlee-Bland G, Lombardo FA, et al. Characteristics and health perceptions of complementary and alternative medicine users in the United States. Am J Med Sci 2015; 349(2): 140-144. doi: 10.1097/MAJ.0000000000000363

41. Green CA, Pope CR. Gender, psychosocial factors and the use of medical services: a longitudinal analysis. Soc Sci Med 1999; 48(10): 1363-1372. doi: 10.1016/S0277-9536(98)00440-7

42. Burke A, Nahin RL, Stussman BJ. Limited health knowledge as a reason for non-use of four common complementary health practices. Plos One 2015; 10(6):e0129336. doi: 10.1371/journal.pone.0129336

43. Zhang $Y$, Lao $L$, Chen $\mathrm{H}$, et al. Acupuncture use among American adults: what acupuncture practitioners can learn from National Health Interview Survey 2007? Evid Based Complement Altern Med 2012; 2012: 1-8. doi: $10.1155 / 2012 / 710750$

44. Al-Windi A. Determinants of complementary alternative medicine (CAM) use. Complement Ther Med 2004; 12(2-3): 99-111. doi: 10.1016/j.ctim.2004.09.007

45. Thomson P, Jones J, Browne M, et al. Psychosocial factors that predict why people use complementary and alternative medicine and continue with its use: a population based study. Complement Ther Clin Pract 2014; 20(4): 302-310. doi: 10.1016/j.ctcp.2014.09.004

46. Bodeker G, Kronenberg F. A public health agenda for traditional, complementary, and alternative medicine. Am J Public Health 2002; 92(10): 1582-1591. doi: 10.2105/AJPH.92.10.1582

47. Saper R. Integrative medicine and health disparities. Glob Adv Health Med 2016; 5(1): 5-8. doi: 10.7453/ gahmj.2015.133

48. Chung VC, Ma PH, Hong LC, et al. Organizational determinants of interprofessional collaboration in integrative health care: systematic review of qualitative studies. PLoS ONE 2012; 7(11):e50022. doi: 10. 1371/journal.pone.0050022

49. Gubb J. Should patients be able to pay top-up fees to receive the treatment they want? Yes. BMJ 2008; 336 (7653): 1104. doi: 10.1136/bmj.39563.453183.AD

50. Department of Health. Liberating the NHS white paper. 2010. https://www.gov.uk/government/ publications/liberating-the-nhs-white-paper (accessed 10 Oct 2018).

51. Polley $M$, Bertotti $M$, Kimberlee $R$, et al. A review of the evidence assessing impact of social prescribing on healthcare demand and cost implications. 2017. https://www.westminster.ac.uk/file/113316/download (accessed 10 Oct 2018).

52. Peters DC, Chaitow L, Harris G et al. Integrating Complementary Therapies in Primary Care. London: Churchill Livingstone, 2002.

53. Michlig $M$, Ausfeld-Hafter $B$, Busato A. Patient satisfaction with primary care: a comparison between conventional care and traditional Chinese medicine. Complement Ther Med 2008; 16(6): 350-358. doi: 10. 1016/j.ctim.2007.12.001

54. Wye L. Mainstreaming complementary therapies into primary care: the role of evidence, 'ideal' service design and delivery and alterations in clinical practice. (A dissertation submitted to University of Bristol). 2007. https://research-information.bristol.ac.uk/files/34502664/446256.pdf (accessed 10 Oct 2018).

55. Wiese $M$, Oster $C$, Pincombe J. Understanding the emerging relationship between complementary medicine and mainstream health care: a review of the literature. Health: (London) 2010; 14(3): 326-342. doi: 10.1177/ 1363459309358594

56. The Kings Fund. What is social prescribing? 2017. https://www.kingsfund.org.uk/publications/socialprescribing. (accessed 10 Oct 2018).

57. Professional Standards Authority. Let's work together. 2016. https://www.professionalstandards.org.uk/ what-we-do/accredited-registers/lets-work-together (accessed 1 Nov 2018).

58. NHS England. Integrated personal commissioning (IPC) . 2015. https://www.england.nhs.uk/commissioning/ $\mathrm{ipc/}$ (accessed 10 Oct 2018).

59. Bloor K. Should patients be able to pay top-up fees to receive the treatment they want? No. BMJ 2008; 336 (7653): 1105. doi: 10.1136/bmj.39563.493218.AD

60. Kmietowicz Z. BMA meeting: doctors call for Royal Commission on copayments. BMJ 2008; 337(jul10 3): a765. doi: 10.1136/bmj.a765 


\section{Survey questionnaire}

Q1

This survey asks about complementary and alternative healthcare practitioners, for example (but not limited to) acupuncture, massage or yoga. This survey only asks about practitioners you have seen, not products you have bought in a shop or self-care at home. Practitioners include therapists and teachers.

In the past 12 months have you seen a complementary or alternative healthcare practitioner for a health-related problem?
A. Yes
B. No
C. Don't know

Please include: Any of the following whether they are NHS professionals or not (e.g. GP, physiotherapist, nurse). For example:
A. Acupuncturist
B. Chinese herbal medicine practitioner
C. Herbalist
D. Homeopath
E. Hypnotherapist
F. Meditation/mindfulness teacher
G. Massage practitioner
H. Chiropractor
I. Osteopath
J. Shiatsu practitioner
K. Tai chi teacher
L. Pilates teacher
M. Yoga teacher
N. Alexander technique teacher
O. Aroma therapist
P. Art therapist
Q. Ayurvedic practitioner
R. Craniosacral therapist
S. Healer (e.g. spiritual healer)
T. Music therapist
U. Nutritional therapist
V. Qi gong teacher
W. Reflexologist
$X$. Reiki practitioner
Y. Anthroposophic medicine practitioner
Z. Bach or other flower remedies practitioner
AA. Biofeedback practitioner
BB. Emotional freedom technique practitioner
CC. Feldenkrais practitioner
DD. Guided imagery practitioner
EE. Traditional medicine practitioner
FF. Trager practitioner
GG. Naturopath
$\mathrm{HH}$. Unani medicine practitioner
Please do not include:
A. Breathing exercises
B. Colour therapy
C. Counselling
D. Dance therapy 
E. Light therapy

F. Neurolinguistic Programming (NLP)

G. Special Diets (e.g. Vegetarianism)

H. Play therapy

I. Psychotherapy

J. Prayer

K. TENS (transcutaneous electrical nerve stimulation)

L. Any treatment which did not involve a practitioner e.g. purchased from a shop or self-care

ASK ONLY THOSE WHO CODE A AT Q1

Q2

What type of practitioner did you see? If you saw more than one, please tell us about the one you have seen the most times in the past 12 months.
A. Acupuncturist
B. Chinese herbal medicine practitioner
C. Herbalist
D. Homeopath
E. Hypnotherapist
F. Meditation/mindfulness teacher
G. Massage practitioner
H. Chiropractor
I. Osteopath
J. Shiatsu practitioner
K. Tai chi teacher
L. Pilates teacher
M. Yoga teacher
N. Alexander technique teacher
O. Aroma therapist
P. Art therapist
Q. Ayurvedic practitioner
R. Craniosacral therapist
S. Healer (e.g. spiritual healer)
T. Music therapist
U. Nutritional therapist
V. Qi gong teacher
W. Reflexologist
$X$. Reiki practitioner
Y. Anthroposophic medicine practitioner
Z. Bach or other flower remedies practitioner
AA. Biofeedback practitioner
BB. Emotional freedom technique practitioner
CC. Feldenkrais practitioner
DD. Guided imagery practitioner
EE. Traditional medical practitioner
FF. Trager practitioner
GG. Naturopath
$\mathrm{HH}$. Unani medicine practitioner
II. Other (please specify)
JJ. Don't know

ASK ONLY THOSE WHO CODE A AT Q1

Q3

And how many times over the past 12 months did you see this complementary practitioner?

A. About once in the past 12 months 
B. About two or three times in the past 12 months

C. About four to six times in the past 12 months

D. About once or twice per month

E. About once or twice per week

F. More than twice a week

G. Don't know

ASK ONLY THOSE WHO CODE A AT Q1

Q4

What were you seeking help for from this complementary practitioner? You can give more than one reason.

Musculoskeletal/pain

A. Back pain

B. Arthritis (osteoarthritis or rheumatoid arthritis)

C. Fibromyalgia

D. Other musculoskeletal pain e.g. neck pain, shoulder pain, knee pain

E. Headaches or migraines

F. Other chronic pain

Mental health

G. Minor mental health symptoms e.g. minor depression, anxiety, stress,

H. Serious mental health conditions e.g. major depression, schizophrenia, bipolar

I. Sleep problems or insomnia

J. Tiredness or fatigue

K. Chronic fatigue syndrome (CFS) or ME

L. Dementia

Other

M. Digestive problems e.g. irritable bowel syndrome, Crohn's disease

N. Preventative i.e. to stay well, prevent ill-health, boost immune system

O. Women's health e.g. period problems, pregnancy, labour, fertility, symptoms of the menopause

P. Cancer

Q. Allergies e.g. hayfever, allergy to dust or animals

R. Skin problems or infections e.g. eczema, psoriasis

S. Cardiovascular problems e.g. heart disease

T. Respiratory problems e.g. cough, colds or flu, asthma, bronchitis, emphysema

U. Infections

V. Diabetes

W. Urinary tract disorders e.g. cystitis, kidney stones, incontinence

$X$. Eye problems

Y. Ear problems

Z. Nervous system problems e.g. stroke, epilepsy, multiple sclerosis

AA. Immune system problems e.g. HIV, autoimmune disease

BB. Other (Please specify)

CC. Don't know

ASK ONLY THOSE WHO CODE A AT Q1

Q5

Which, if any of these, describes how you came to use this complementary treatment?

A. My GP referred or recommended me

B. Another NHS health professional (e.g. consultant) referred me

C. My GP or another NHS health professional I was seeing provided the complementary treatment themselves

D. Another complementary practitioner referred or recommended me

E. I found them myself/ they were recommended by friend/family 
F. Other (please specify)

G. Don't know/can't remember

ASK ONLY THOSE WHO CODE A AT Q1

Q6

How was the treatment from this complementary practitioner paid for? Please select all that apply.

A. The NHS paid for all or part of it

B. I or my family/friend paid for all or part of it

C. Another organisation such as a charity paid for all or part of it

D. My health insurance paid for all or part of it

E. I don't know/ don't remember

F. Other (please specify)

ASK ONLY THOSE WHO CODE B AT Q6

Q7

On average, how much did you pay for each visit to this complementary practitioner?

A. Less than $f 10$

B. Between $f 11$ and $£ 20$

C. Between $\mathrm{f} 21$ and $£ 30$

D. Between $£ 31$ and $£ 40$

E. Between $£ 41$ and $£ 50$

$F$. Between $£ 51$ and $£ 60$

G. Between $£ 60$ and $£ 100$

H. Over $f 100$

I. I don't know/don't remember

J. Prefer not to say

ASK ONLY THOSE WHO CODE B AT Q1

Q8

Please can you tell me why not?

A. I wasn't seeking help for any health problems/ I didn't have any health problems

B. It hasn't occurred to me

C. I don't know enough about it

D. I don't have time

E. I don't think it would help me

F. I don't believe in it

G. I'm afraid of the side effects/ how it interacts with other medicines

$\mathrm{H}$. I am concerned about the practitioner not being qualified or regulated

I. My GP/other NHS health professional has advised against it

$\mathrm{J}$. It is not available on the NHS

K. It is not available locally

L. I can't afford to pay for it

M. Other, (please specify)

N. Prefer not to say

O. Don't know

ASK ALL

Q9 
If you had a health problem you thought complementary or alternative medicine could help with, which, if any, of the following statements would encourage you to use it?

A. If it was free through the NHS or another organisation/ charity

B. If it was partly paid for by the NHS or another organisation/ charity (I only had to pay a small amount)

C. If the complementary practitioner was also an NHS health professional

D. If the complementary practitioner was based in an NHS setting

E. If the NHS regulated the complementary practitioner

F. If my GP mentioned it might help

G. If my GP referred me to the complementary practitioner

$\mathrm{H}$. If I thought it would enhance the care I was already receiving

I. If I had to wait a long time for NHS care

J. If my NHS treatment was not helping me

K. None of the above

L. Other (please specify)

M. I would never use it

N. Don't know

ASK THOSE WHO CODE B AT Q1. DO NOT INCLUDE THOSE WHO CODE M AT Q9

Q10

If you had a health problem you thought would improve from seeing a complementary or alternative practitioner, what is the most you would be willing to pay for each visit?

f0

- Less than $f 10$

- Between $f 11$ and $f 20$

Between $£ 21$ and $£ 30$

Between $£ 31$ and $£ 40$

Between $£ 41$ and $£ 50$

Between $£ 51$ and $£ 60$

Between $f 60$ and $£ 100$

- Over $£ 100$

I don't know

- Prefer not to say 